\title{
PLATÃO E DERRIDA, PENSADORES DA DIFERENÇA
}

Plato and Derrida as thinkers of the difference

Felipe Castelo Branco*

Resumo: O objetivo deste artigo é o de empreender uma breve análise da forma como a questão da diferença é tratada no pensamento do Platão e de Jacques Derrida. $\mathrm{O}$ interesse que perpassa todo o trabalho é o de apontar como o conceito de diferença pôde ser pensado em sua referência fundamental ao ser e à ontologia (em Platão), ou contra a ontologia (em Derrida). Para isso, será preciso estudar o Sofista de Platão e o artigo La différance de Derrida, trabalhos onde o problema da diferença ganha relevo especial.

Palavras-chave: Diferença. Descontrução.

\begin{abstract}
This work's aim is to make a brief analysis on the way difference is treated in Plato's and Derrida's work. One tries to show how the concept of difference could be thought in reference on being and ontology (in Plato) and against ontology (in Derrida). For that, it will be necessary to study Plato's Sofist and Derrida's La différance as well. Both are works where the concept of difference have a special place. Keywords: Difference. Deconstruction. Genres.
\end{abstract}

\section{Gêneros.}

* Doutorando em Filosofia pela Pontíficia Universidade Católica do Rio de Janeiro (PUC-Rio). Contato: felipe.castelobranco@yahoo.com.br

\begin{tabular}{|c|c|c|c|c|c|}
\hline intuitio & $\begin{array}{c}\text { ISSN } \\
1983-4012\end{array}$ & Porto Alegre & Vol.7 $-\mathrm{N}^{\mathrm{o}} .2$ & $\begin{array}{c}\text { Novembro } \\
2014\end{array}$ & p. 197-213 \\
\hline
\end{tabular}




\section{Introdução: Platão, Derrida e a diferença}

Jacques Derrida é reconhecido no contexto da história da filosofia contemporânea como um pensador da diferença. Embora o problema da diferença tenha atravessado o pensamento de uma miríade de filósofos no passado, a filosofia de Derrida teria sido responsável por recuperar a questão da diferença em nova chave. Se tal afirmação é verdadeira, no outro extremo da linha cronológica que desagua na desconstrução derridiana encontra-se forçosamente o pensamento de Platão como um dos inauguradores do questionamento sobre o problema da diferença no campo filosófico.

Este breve artigo tratará de alguns aspectos da questão da diferença em Derrida e igualmente em Platão, nem sempre de modo comparativo. Contudo, será dado destaque aos pontos de contato e de divergência entre ambos os pensadores no que diz respeito a este tema. Derrida foi possivelmente um dos pensadores contemporâneos que mais frequentemente recorreu ao pensamento de Platão como possível interlocutor filosófico na tentativa de pensar "problemas contemporâneos". Desde A farmácia de Platão ${ }^{1}$, que tratava de pensar o problema da escrita na última parte do Timeu, e posteriormente em Khôra ${ }^{2}$, que se ocupava do problema do conceito platônico de Khora - espécie de receptáculo que Platão localiza entre o âmbito sensível e o âmbito das formas e que o texto derridiano tomava como um conceito indecidível -, o vínculo entre a filosofia do pensador franco-argelino e o pensador grego se sedimentava e tornava-se reconhecidamente frutífero. No entanto, no que diz respeito ao seu quaseconceito de maior destaque, a saber, o conceito de différance ${ }^{3}$, Derrida não faz nenhum recurso explícito à Platão no artigo em que o constrói e analisa suas ressonâncias. Será precisamente o reestabelecimento deste vínculo no que diz respeito à diferença que o presente artigo tratará de desenvolver de maneira breve.

Contudo, os problemas se apresentam no instante mesmo onde buscamos decidir o modo de abordagem do problema. Se, por um lado, Platão vai pensar a questão da diferença no texto do Sofista em um vínculo estreito e necessário com o problema do ser e, mais especialmente, com o problema do não-ser (além, evidentemente, das ideias do mesmo, do repouso e do movimento); Derrida, por outro

\footnotetext{
${ }^{1}$ Cf. DERRIDA, J. "La pharmacie de Platon". in: La dissémination. Paris: Seuil, 1972b.

${ }^{2}$ Cf. DERRIDA, J. Khôra. Paris: Galilée, 1993.

${ }^{3}$ É sabido que Derrida grafa a palavra francesa différence de maneira diferente quando se trata de seu quaseconceito, introduzindo na palavra corrente da língua francesa a letra "a" onde habitualmente a língua ordinária grafaria "e". Tal modificação, contudo, não altera a expressão fonética do termo (ambos os termos são homfônicos), mas apenas a expressão grafada, escrita. Assim, a différance derridiana marcaria o vínculo entre a diferença e a escrita, ao mesmo tempo em que possibilita um recurso, diríamos, anti-estético, ao mostrar que a différance não se apresenta enquanto tal, enquanto fenômeno, mas permanece vinculada a um rastro jamais totalmente positivo. Desenvolveremos ao longo deste artigo o problema da différance em sua questão teórica. Contudo, é preciso alertar ao leitor que não encontramos um correlato em língua portuguesa para o recurso que Derrida lança mão ao modificar a grafia da palavra francesa. Todas as alternativas propostas até o momento para as traduções ao português carregam o inconveniente de serem incapazes de atingir a grafia sem atingir a expressão fonética, ou o contrário (como a grafia por 'diferencia'). Por esta razão, se convencionou manter a grafia que Derrida alterava, tal como ele fazia em francês, mesmo no texto em português.

${ }^{4}$ Cf. PLATÃO. Sofista (ou do Ser). Trad.: Bini, E. In: Diálogos I. Bauru/São Paulo: Edipro, 2007.
}

\begin{tabular}{|c|c|l|l|l|l|}
\hline intuitio & $\begin{array}{c}\text { ISSN } \\
1983-4012\end{array}$ & Porto Alegre & Vol.7- $\mathrm{N}^{\mathrm{o} .2}$ & $\begin{array}{c}\text { Novembro } \\
2014\end{array}$ & p. 197-213 \\
\hline
\end{tabular}


lado, rejeita qualquer referência à ontologia e ao problema do ser ${ }^{5}$ em seu percurso de reflexão sobre a diferença. Portanto, será preciso apresentar ao leitor de que maneira o problema da diferença nutre certa dependência em relação à questão do ser em Platão, via não-ser. E, do mesmo modo, como Derrida é capaz de dispensar uma referência ao ser e pensar a questão da diferença sem ter que se ancorar sobre qualquer concepção ontológica.

Antes disso, é preciso compreender certa "cronologia" da diferença. Tanto em Platão quanto em Derrida, a questão da diferença é igualmente a abertura e a condição da questão do outro (heteron). Ora, a alteridade permanece sendo o problema que perpassa todas as concepções que estudaremos e constitui o problema fundamental que buscamos explorar. No Sofista, antes de ser o motor fundamental da dialética responsável pela divisão dos seres e diferenciação segundo as formas, a diferença pode ser encarada também de um ponto de vista "antropológico". Não se trata de argumentar em favor de uma preponderância da dimensão antropológica sobre a dimensão ontológica no diálogo, o que não seria de grande valia para nosso comentário. Trata-se apenas de apontar o recurso que Platão faz ao personagem do Estrangeiro no diálogo, e sua relação ao problema do parricídio das concepções parmenídicas. Não é anódino que Platão recorra à figura do estrangeiro, de um estrangeiro eleata, para - via sofista - cumprir a tarefa de produzir um parricídio sobre o pai da filosofia e do pensamento sobre o ser, isto é, Parmênides. O outro do filósofo - o sofista -, assim como o outro do grego - o estrangeiro -, terão uma função fundamental na elucidação de todo pensamento construído sob a luz do problema da diferença em Platão.

O Estrangeiro, esse outro do grego, admitido no seio da cidade, ao mesmo tempo em que é obrigado a ocupar um lugar que o marca como sendo diferente do cidadão ateniense, será aquele que Platão dará voz, no ousado empreendimento de executar um parricídio ao pensamento do "pai de todos" os filósofos, isto é, Parmênides. Tudo se passa como se o Estrangeiro pudesse ser aquele que coloca $a$ questão, que questiona, e porta a questão por seu próprio estatuto de estrangeiro. $\mathrm{O}$ Estrangeiro como aquele que coloca a questão para tudo aquilo que é familiar. O Estrangeiro coloca em questão o logos parmenídico e abala o dogmatismo do ser de Parmênides. Com isso, ele toca a questão do não-ser, questão que toca o âmbito onde o sofista estabeleceu sua morada. Mas, ao mesmo tempo, um parricida só pode ser aquele que mata o pai, sendo filho daquele que ele próprio assassina, filho do logos que ele abala (o Estrangeiro é também um eleata). O Estrangeiro, dirá Derrida, ao mesmo tempo em que permanece no exterior da cena familiar platônica, pede para ser recebido, acolhido, requisita hospitalidade, pede entrada e reconhecimento na cena de família.

Ousar questionar se o não-ser de alguma forma é, ousar colocar a questão do não-ser, contudo, exige um preço. Por esse motivo, o Estrangeiro teme ser tomado por louco. Imediatamente, ele pede para que não o encarem como um maniakos. Colocar-se fora do logos, colocar a questão contra do logos fundado por Parmênides, ameaça manchar o portador da questão, o estrangeiro, com a marca da

${ }^{5}$ Derrida rejeita inclusive a polaridade ou a oposição/parentesco entre o não-ser e o ser. O pensamento derridiano compreende o sofista como uma extensão e uma continuidade necessária da ontologia filosófica.

\begin{tabular}{|c|c|l|l|l|l|}
\hline intuitio & $\begin{array}{c}\text { ISSN } \\
1983-4012\end{array}$ & Porto Alegre & Vol.7- $\mathrm{N}^{\mathrm{o} .2}$ & $\begin{array}{c}\text { Novembro } \\
2014\end{array}$ & p. 197-213 \\
\hline
\end{tabular}


loucura. Fora do logos, nesse mundo obscuro fora do discurso, nada há! Aquele que opta pelo mais além do logos só pode ter optado pelo vazio da razão, isto é, pela loucura propriamente.

Mas o Estrangeiro se defende, antecipadamente, da acusação de louco. Ele requisita ser ouvido pelos filhos do logos, ele demanda hospitalidade, pede que sua questão seja considerada, ele que é aquele que ousa colocar a questão temida, a questão intolerável. Portanto, a questão da diferença no diálogo platônico se inicia aqui: aquele que conduz a questão, que direciona a pesquisa é, ele mesmo, o outro - a diferença - em relação ao tradicional filósofo ateniense, assim como a questão colocada é outra, é a própria diferença em relação à questão filosófica tradicional. Derrida lembra que Sócrates igualmente, em Apologia de Sócrates, argumenta diante do tribunal que, não sendo um sofista e por não compartilhar da retórica jurídica praticada nos tribunais (e igualmente em meio aos sofistas), ele é como um ksenos, um estrangeiro - aquele que coloca a questão de modo diferente, aquele que pensa os problemas de modo inabitual ou de uma maneira que não se pensa em meio àquela reunião de pessoas. Para Derrida, é precisamente aí que se inaugura a questão do lugar do estrangeiro e do problema da hospitalidade: "devemos pedir ao estrangeiro que nos compreenda, que fale nossa língua, em todos os sentidos do termo, em todas as extensões possíveis, antes e afim de poder acolhê-lo entre nós?”“ Devemos, portanto, rejeitar a questão do estrangeiro? Devemos traduzir em nossa língua o estrangeiro como tal? Devemos toma-lo como louco, encarar como uma espécie de insanidade sua saída do logos? Ou devemos acolher tal questão, mesmo que a questão "não fale nossa língua"? Ainda que a questão defenda certo modo de ser do não-ser? Mesmo que a questão temida, estrangeira, abale o lugar patriarcal legado à Parmênides?

A questão de Platão no Sofista é uma questão vinda do outro. É a própria vinda do outro que está em questão. Mas o estrangeiro não é o bárbaro. Em Atenas, o estrangeiro, dentro de seu estatuto de "outro", é dotado de direitos igualmente. O estrangeiro, em meio aos atenienses, detinha o direito de acesso aos tribunais e, portanto, tinha garantido para si certo espaço de fala. Sua voz era detentora de um espaço para ser ouvida, o estrangeiro era livre para portar a questão e colocar questões aos cidadãos. É precisamente aí que a argumentação de Sócrates diante do tribunal que o condenaria ganha todo seu peso. Sócrates se queixa de não ser tratado nem mesmo como um estrangeiro pelos juízes atenienses. Ele aponta que sua voz foi silenciada, sendo tratado como um bárbaro - este sim, sem direitos políticos, sendo considerado, aos olhos dos Atenienses, incapaz até mesmo de falar uma língua compreensível -, diante de um tribunal que não reconhece o alcance de sua questão, diante de um tribunal que não lhe dá ouvidos:

Qual é a sutileza retórica socrática, da postulação de Sócrates, o Ateniense? Ela consiste em queixar-se de não ser sequer tratado como estrangeiro: se eu fosse estrangeiro, vós aceitaríeis com mais tolerância que eu não fale como vós, que eu tenha meu idioma, minha maneira tão pouco técnica tão pouco jurídica de falar, uma maneira que é ao mesmo tempo a mais popular e a mais filosófica. Que o estrangeiro, o ksénos, não seja simplesmente o outro absoluto, o bárbaro, o selvagem absolutamente excluído e heterogêneo [...] trata-se de saber se esse pacto, esse

${ }^{6}$ DERRIDA, J; DUfOURMANTELLE, A. Da hospitalidade. Trad.: Romane, A. São Paulo: Escuta, 2003, p.15.

\begin{tabular}{|c|c|l|l|l|l|}
\hline intuitio & $\begin{array}{c}\text { ISSN } \\
1983-4012\end{array}$ & Porto Alegre & Vol.7- $\mathrm{N}^{\mathrm{o}} .2$ & $\begin{array}{c}\text { Novembro } \\
2014\end{array}$ & p. 197-213 \\
\hline
\end{tabular}


contrato de hospitalidade [entre o ateniense e o estrangeiro] que liga ao estrangeiro e que liga reciprocamente o estrangeiro, vale para além do indivíduo e estende-se, assim, a toda a família, à geração, à genealogia [...] para começar, o direito à hospitalidade pressupõe uma casa, uma linhagem, uma família, um grupo familiar ou étnico recebendo um grupo familiar ou étnico [...] a diferença, uma das mais sutis diferenças, às vezes imperceptíveis entre o estrangeiro e o outro absoluto, é que este último pode não ter nome e nome de família; a hospitalidade absoluta ou incondicional que eu gostaria de oferecer a ele supõe uma ruptura com a hospitalidade no sentido corrente, com a hospitalidade condicional, com o direito ou o pacto de hospitalidade ${ }^{7}$.

Ora, receber o outro, abrir-se para a questão do outro, do outro "enquanto tal", pressupõe uma ruptura mesmo com o pacto de hospitalidade estabelecido entre o estrangeiro e o ateniense. $\mathrm{O}$ estrangeiro, o outro reconhecido pelo ateniense, reforça a propriedade que o ateniense tem sobre seu sangue e sua terra. Em Atenas, o estrangeiro é recebido pelo cidadão ateniense que permanece falando sua própria língua, dentro do amparo de suas leis e de sua própria religião. $\mathrm{O}$ estatuto do estrangeiro, para o ateniense, é precisamente o estatuto de um outro que reforça o mesmo, o outro que não ameaça ou desloca o "si mesmo" que é o cidadão ateniense. O estrangeiro é um outro filtrado e traduzido pelo "si". Derrida propõe, por outro lado, uma abertura para o outro que não esteja amparada pelo pacto de mesmidade. Para além disso, Derrida propõe prática de uma hospitalidade capaz de receber um outro sem nome, sem estatuto prévio ou estável. Abertura para a vinda do outro radical. Uma questão que porte em si a diferença enquanto tal. Uma forma da diferença que não dependa do estabelecimento da mesmidade: uma diferença independente dos parâmetros do "si mesmo". Veremos adiante como esta forma da diferença aparece no texto de Platão.

A segunda forma antropológica de expressão do outro no diálogo de Platão será justamente a figura do sofista. O objetivo primeiro do diálogo Sofista era o de buscar, precisamente, uma definição do sofista. No entanto, como é sabido, ao buscar o sofista, a pesquisa do diálogo encontra o filósofo. Se Parmênides, pai da filosofia, fez do não-ser uma espécie de âmbito intocável fora do discurso ou do logos, um sofista como Górgias - de maneira integralmente dependente do discurso parmenídico -, colocando-se do ponto de vista do não-ser como avesso ao ser do filósofo, reivindica o mundo obscuro do não-ser que soa ao ouvido do filósofo como uma fala absurda, acrítica. Para chegar às teses do sofista, Platão vai precisar atingir as teses filosóficas do próprio Parmênides em sua coluna vertebral: ao buscar o sofista, Platão encontra o filósofo como seu outro complementar. Ao mergulhar no campo do não-ser, campo de batalha onde o sofista conquistou o terreno, Platão encontra uma forma inovadora (e dialética) de pensar o ser e os chamados gêneros maiores. A definição do sofista toca diretamente, portanto, a definição do filósofo: um se define a partir e contra o outro. A filosofia platônica, no entanto, se interessa pela questão do ser e do outro ou da diferença de forma dialética, e sua pretensão em relação a alteridade seria aquilo que marcaria definitivamente seu discurso sobre o

\footnotetext{
${ }^{7}$ DERRIDA, J; DUfOURMANTElle, A. Da hospitalidade. Trad.: Romane, A. São Paulo: Escuta, 2003, pp. 19-23.

\begin{tabular}{|c|c|l|l|c|c|}
\hline intuitio & $\begin{array}{c}\text { ISSN } \\
1983-4012\end{array}$ & Porto Alegre & Vol.7- $\mathrm{N}^{\mathrm{o} .2}$ & $\begin{array}{c}\text { Novembro } \\
2014\end{array}$ & p. 197-213 \\
\hline
\end{tabular}
}


ser. Assim, atingimos o laço que liga a dimensão "antropológica" e a dimensão "ontológica" do diálogo:

A caça ao sofista adquire um alcance ontológico essencial que é a questão da filosofia por excelência: a possibilidade de dizer o ser, dizer o que é. Este cruzamento de perspectivas é o coração aporético do diálogo, o que liga as dimensões antropológica e ontológica da caça ao sofista. [...] Mas só saímos do domínio das trocas humanas (as técnicas do sofista), indo na direção dos gêneros maiores, para podermos voltar a ele: ao final do diálogo, a divisão é retomada, para definir a técnica do sofista ${ }^{8}$.

\section{Platão, o não-ser e a diferença}

Será Platão um pensador da representação, da unidade, do ser e das formas, capaz de estabelecer uma filosofia grandiosa sem jamais levar em consideração a diferença, a alteridade, o nãoser, a não-representação? Parece um tanto forçado afirmar que um pensador possa ser tão dogmático, a ponto de produzir uma cisão no pensamento (sensível x forma, mesmo x diferença, etc.), sem jamais levar em consideração os conceitos problemáticos e questões dedutíveis necessariamente de suas próprias posições teóricas e de suas escolhas filosóficas. Tal vulgata do pensamento platônico, muitas vezes em voga e útil na construção de um rival teórico francamente artificial, não nos parece válida para a construção de um diálogo capaz de tecer problemas de fato interessantes para a teoria.

Platão foi também um pensador da diferença e do outro (héteron). E o diálogo Sofista é provavelmente a obra onde tal problemática se torna mais evidente e nuançada. No entanto, para pensar o problema da diferença, Platão teve que atravessar algumas aporias oriundas da problemática do não-ser - herdadas, evidentemente, dos sofistas - e também, posteriormente, ele teve que repensar algumas aporias concernentes ao próprio problema do ser. Partiremos de tais aporias na intenção de compreender o lugar da diferença na divisão dos gêneros e em sua mistura ou entrelaçamento (symploké) neste diálogo. Portanto, vamos trabalhar com um momento bastante específico do diálogo, mas que nos conduzirá ao coração do problema que nos interessa explorar.

Iniciamos nossa problemática com a análise que Teeteto e o Estrangeiro empreendem do ser, submetendo este conceito às teses dos materialistas, chamados no diálogo de filhos da terra, e, sem seguida, submetendo o conceito de ser às teses rivais dos idealistas, aqui nomeados de amigos das formas. Os primeiros, que "arrastam tudo do céu e do invisível para a terra" (246a), são fundamentalmente reconhecidos por identificar ser e corpo, afirmando, a partir daí, que tudo aquilo que é tem que ser manuseável, tangível. O Estrangeiro submete, então, às teses materialistas, as antíteses idealistas, praticando in loco essa "batalha interminável" (246c) entre essas duas concepções. Ora, se materialistas identificam o ser ao corpo e à materialidade, eles supõem que o vivo, tudo aquilo que é dotado de vida, corresponde, por sua vez, a um corpo dotado de alma. Ora, tal corpo animado tem que pressupor que a noção de alma está presente entre os entes ditos vivos. Mas isso não é ainda

\footnotetext{
${ }^{8}$ MARQUES, M. P. Platão, pensador da diferença: uma leitura do Sofista. Belo Horizonte: UFMG, 2006, p.36.
}

\begin{tabular}{|c|c|l|l|c|c|}
\hline intuitio & $\begin{array}{c}\text { ISSN } \\
1983-4012\end{array}$ & Porto Alegre & Vol.7- $\mathrm{N}^{\mathrm{o} .2}$ & $\begin{array}{c}\text { Novembro } \\
2014\end{array}$ & p. 197-213 \\
\hline
\end{tabular}


suficiente na argumentação do Estrangeiro. Esses corpos animados podem ser igualmente justos ou injustos, isto é, eles equivaleriam a corpos dotados de uma alma justa ou injusta, sábia ou virtuosa. Portanto, ao supor que justiça, sabedoria, virtude são características presentes $n a$ alma, os materialistas fornecem a chave para sua própria contradição: sua tese tem que admitir que tais qualidades da alma são igualmente dotadas de ser. Se a alma é dotada de justiça, por exemplo, e a própria justiça é dotada de ser, o materialista, ao mesmo tempo, tem que reconhecer forçosamente que o ser da justiça não é dotado de corpo, não podendo ser reduzido à matéria. Ao reconhecer o ser da virtude, da justiça, etc., os materialistas são pegos em uma flagrante contradição, admitindo a existência de seres corpóreos $e$ incorpóreos, o que nos leva à conclusão de que a corporeidade não pode ser um critério exclusivo de definição do ser (conclusão deduzida das próprias teses materialistas em sua franca contradição).

Ao reconhecer que o ser não é sempre dotado de corporeidade, os materialistas, portanto, reconhecem, ato contínuo, a tese dos amigos das formas. Mas para o Estrangeiro não basta admitir que o ser é incorpóreo, satisfazendo-se com a antítese ao pensamento materialista, tese que poderia ser facilmente conduzida à contradição. Para além da polaridade, trata-se de conciliar as duas teses, reunindo ambas em um gênero comum. Assim, a estratégia do Estrangeiro passa por propor uma definição do ser como potência (dynamis). Definido deste modo, o ser é considerado como algo capaz de agir sobre outra coisa ou de sofrer a ação. Tal definição se propõe como uma espécie de superação das polaridades ou da batalha entre materialistas e idealistas, ao mesmo tempo em que funda uma reconciliação entre ambas as perspectivas.

A aproximação entre ser e dynamis, a definição do ser como potência, ainda que funcione como superação da problemática polaridade entre materialistas e idealistas, vai precisar ser posta à prova a fim de resistir a qualquer forma de refutação. Na sequência, a definição do ser como potência (mais especificamente como potência de agir), submete-se a prova pela via do problema do conhecimento. O Estrangeiro propõe que o ato de conhecimento seria um ato da alma cognoscente sobre o que é conhecido. A posição ativa do conhecer sobre a posição passiva do ser conhecido, permite deduzir que o ser que é conhecido, ao sofrer a ação, é movido; deste modo, o problema do movimento - ativo no caso do ato de conhecer e passivo no ato de ser conhecido -, é introduzido na questão mesma do ser. O problema do movimento inaugura no diálogo o que será conhecido adiante como a questão dos gêneros.

O ser não pode ser imóvel nem é sem vida. Essa problemática do conhecimento e do movimento inaugurada pelo Estrangeiro nos permite admitir uma dupla conclusão. Em primeiro lugar, podemos admitir que aquilo que é movido, é dotado de ser: o movido é. Em seguida, podemos igualmente afirmar que o ser é dotado de movimento (e justamente por ser "dotado da potência" do movimento, isto é, por participar do movimento, ele é capaz de mover). Sem movimento, seria impossível conhecer, ou seja, mover o conhecido no ato de conhecimento. O laço entre ser e movimento se funda neste momento de maneira indelével. No entanto, uma vez mais, o Estrangeiro recusa pender apenas para um lado ou para um único aspecto da problemática. Assim, ele recusa do

\begin{tabular}{|c|c|l|l|c|c|}
\hline intuitio & $\begin{array}{c}\text { ISSN } \\
1983-4012\end{array}$ & Porto Alegre & Vol.7- $\mathrm{N}^{\mathrm{o} .2}$ & $\begin{array}{c}\text { Novembro } \\
2014\end{array}$ & p. 197-213 \\
\hline
\end{tabular}


mesmo modo tanto a tese de afirmaria que o ser seria puro repouso - em uma unidade ou mesmo em meio à multiplicidade -, quanto a tese, já bastante conhecida, que afirmaria que o ser seria puro movimento. Essa tese defenderia uma espécie de movimento universal, sem repouso e sem estabilidade, no seio mesmo do ser (tese defendida por partidários do heraclitismo). Ora, abolir a estabilidade das formas seria igualmente nocivo à definição do ser adquirida até aqui. O conhecimento das coisas requisita certa imobilidade do objeto para que o ato mesmo de conhecer possa ser deduzido como movimento. É preciso estabilidade para que o movimento do ato de conhecimento se imprima sobre o que é conhecido. Ao adquirir a comunicação entre o ser e o movimento, o Estrangeiro não excluiu o repouso de suas considerações sobre o ser, mas, ao contrário, ele acrescenta a essa problemática a própria relação necessária entre repouso e movimento. Nesse panorama, a imobilidade, assim como o movimento, devem ser, portanto, de maneira equivalente, considerados no âmbito do ser. O ser deve sua caracterização igualmente tanto ao movimento quanto ao repouso.

Aqui se forma o problema maior que a pesquisa do Sofista tem que enfrentar. Se repouso e movimento são igualmente e da mesma maneira, não podemos jamais afirmar que o ser ou é repouso $o u$ é movimento. Não podemos oferecer ao ser a caracterização exclusiva de um dos dois polos. Se tendêssemos a caracterizar o ser a partir de um dos dois termos, excluindo a participação do outro termo no campo do ser, cairíamos em contradição no que diz respeito a estabilidade e ao movimento em seu laço com o ente. Tal possibilidade já foi superada. E, no entanto, repouso e movimento são opostos e contraditórios. Então, como proceder? Ora, não podemos igualmente afirmar do ser uma caracterização tão contraditória, incluindo a participação de opostos nesse único termo geral, o ser, sob pena de nos perdermos no caminho da pesquisa. O Estrangeiro proporá então que o ser deve ser uma terceira coisa, nem repouso nem movimento, mas uma terceira instância capaz de abarcar a ambos de maneira associada. O ser não pode, ele mesmo, estar permanentemente nem em repouso nem em movimento. Ou, dito de outro modo, se movimento e repouso são duas coisas que são, não podemos reduzir o ser a nenhum desses dois elementos exclusivamente. Admitindo que o ser é terceiro em relação a ambos, podemos finalmente admitir que movimento e repouso só são em referência e comunicação com este terceiro gênero que é o ser.

Assim, começamos paulatinamente a orbitar em torno do problema da diferença. Será a diferença do ser em relação ao movimento e ao repouso que fornecerá a cada um destes elementos sua "natureza" própria. O ser, sendo outro em relação a estes dois gêneros, é, ao mesmo tempo, o que torna possível sua constituição. Ora, somente aí será possível analisar a diferença de movimento e repouso entre si, e de ambos em relação ao ser. Tocamos, aqui, nos dois sentidos da diferença no texto do Sofista: em primeiro lugar como oposição à identidade - ou ao idêntico. O ser, em relação ao movimento e ao repouso, é diferente; sendo cada termo outro em relação aos outros termos em questão. Eis a diferença em sua face de relação. Em segundo lugar, temos a diferença como ausência de participação: o movimento não participa do repouso (e também ao contrário), ainda que o ser

\begin{tabular}{|c|c|l|l|c|c|}
\hline intuitio & $\begin{array}{c}\text { ISSN } \\
1983-4012\end{array}$ & Porto Alegre & Vol.7- $\mathrm{N}^{\mathrm{o}} .2$ & $\begin{array}{c}\text { Novembro } \\
2014\end{array}$ & p. 197-213 \\
\hline
\end{tabular}


participe de ambos. É essa ausência de participação, precisamente, que possibilita que movimento e repouso sejam contrários e contraditórios.

Mas retomemos o caminho do diálogo. O ser não se identifica a seus próprios atributos, mas compartilha com movimento e repouso a possibilidade de ambos participarem de seu círculo ao mesmo tempo. É precisamente a esta conclusão que chega a pesquisa do Sofista, quando, através do chamado "paradigma das letras", Teeteto e o Estrangeiro admitem que algumas coisas se mesclam entre si, enquanto outras não se mesclam. Tal como a relação entre as vogais e consoantes no alfabeto, algumas coisas funcionam como uma espécie de liame, de ligação ou combinação entre letras que não poderiam, por si mesmas, serem combinadas e tal é o papel das vogais com relação às consoantes. Logo, enquanto movimento e repouso se repelem e não se combinam, ambos são, por outro lado, capazes de participar e de se combinar ao ser. A tentativa de dar conta do problema da mescla ou da combinação se evidencia na ampla terminologia que Platão se utiliza constantemente nas passagens que se seguem, e que participam de um mesmo campo semântico: koinonêin, sumplokeîn, summeígnusthai - para mencionar apenas alguns termos -, que remetem, respectivamente, a comunicar, entrelaçar e misturar. Mas é preciso dar destaque ao fato de que, sob o fundo da questão da combinação e da mistura, já se apresenta, sub-repticiamente, a questão da diferença que veremos se explicitar mais evidentemente adiante:

Há sempre diferença subjacente a todas as combinações, mas há também diferença quando não há nenhuma combinação; a partir do fundo de diferença, diversas relações podem se constituir, sem que uma seja equivalente a outra, mas também pode não ocorrer nenhuma relação. Movimento e repouso, por exemplo, mesmo sendo diferentes, não combinam um com o outro, enquanto movimento e ser, também diferentes, o fazem. A diferença é, portanto, condição necessária, mas não suficiente, para que haja combinação ${ }^{10}$.

A pesquisa do diálogo encontrou no ser algo que escapa à definição estrita. Esse caráter indefinível do ser se deve ao fato de que ele perpassa os elementos que dele fazem parte, sem jamais se reduzir a nenhum deles. Mas no que diz respeito aos elementos que comungam com o ser - ou seja, repouso e movimento até aqui -, cada um deles é diferente (héteron) e guarda uma relação de alteridade com o outro. E, enquanto diferente, o outro tem que ser, igualmente, o mesmo (tauton) em relação a si. Assim, temos estabelecida uma relação de mesmidade, onde o ser si mesmo se afirma por diferença em relação ao outro. Mas há também a relação de ipseidade, onde o ser que é deve ser idêntico a si, afirmado a partir de si, sem vínculo de diferença com relação a outrem. Movimento e repouso devem ser idênticos, cada qual a si mesmo, sendo, ao mesmo tempo, diferentes um em relação ao outro. Assim, o repouso não participa do movimento e do mesmo modo seu contrário não pode ser afirmado

\footnotetext{
${ }^{9}$ GOLDSCHIMIDT, V. Os diálogos de Platão: estrutura e método dialético. São Paulo: Loyola, 2010, p.170.

${ }^{10}$ MARQUES, M. P. Platão, pensador da diferença: uma leitura do Sofista. Belo Horizonte: UFMG, 2006, p.210.
}

\begin{tabular}{|c|c|l|l|c|c|}
\hline intuitio & $\begin{array}{c}\text { ISSN } \\
1983-4012\end{array}$ & Porto Alegre & Vol.7- $\mathrm{N}^{\mathrm{o} .2}$ & $\begin{array}{c}\text { Novembro } \\
2014\end{array}$ & p. 197-213 \\
\hline
\end{tabular}


A partir daí surge uma dificuldade no caminho da pesquisa: se afirmo que o repouso é, isto é, que ele participa do ser, e afirmo igualmente que o movimento é, por outro lado, já admitimos que, mesmo ambos participando do ser, repouso e movimento não partilham a mesma natureza, devendo ser o mesmo (cada qual em relação a si). Portanto, ambos participam do ser e, como acabamos de afirmar, participam do mesmo. Mas seria o mesmo idêntico ao ser? Se repouso e movimento participam do ser - fato que lhes oferece a possibilidade de aceder ao logos, de serem pensados ou falados -, e ambos participam igualmente do mesmo - sendo cada qual idêntico a si -, não estaríamos autorizados a afirmar que o ser e o mesmo são a mesma coisa? O Estrangeiro nos mostra, a partir deste questionamento, que se o mesmo não for um gênero diferente de ser; ao afirmarmos que repouso e movimento são e participam do mesmo, ato contínuo, estaríamos afirmando que ambos são idênticos (um em relação ao outro), isto é, que ambos são apenas enquanto são a mesma coisa. Ora, já afirmamos a diferença entre repouso e movimento. Logo, o ser e o mesmo devem ser diferentes entre si. Afirmando que repouso e movimento participam do ser e que, igualmente, ambos participam do mesmo, ao mesmo tempo em que afirmamos que o ser e o mesmo tem que ser diferentes, somos levados a concluir, junto com o Estrangeiro, que o mesmo seria um quarto gênero que se soma aos outros três mégista géne, isto é, aos outros gêneros maiores que são o ser, o repouso e o movimento.

Ficará ainda mais evidente a participação do outro ou da diferença na composição dos quatro gêneros até agora estabelecidos. Tudo aquilo que é, foi pensado até aqui como algo que é "em si mesmo", auta kath 'hautá, ou ainda, por outro lado, algo que é "em relação a outros, pros alla. Afirmamos, assim, a ipseidade, por um lado, e a mesmidade, por outro lado - o ser si mesmo por relação a si, e o ser si mesmo por diferença em relação ao outro. O que significa que aquilo que é, ou é absolutamente, ou é de maneira relativa, isto é, participa do ser por diferença em relação a outrem. Portanto, a diferença, de maneira relativa, como possibilidade de ser enquanto alteridade, "legitimaria" igualmente o ser. Encontramos aqui, desta vez, um vínculo entre ser e diferença. Resta agora pensar se o diferente (héteron), que permanece ao fundo do laço que unia os gêneros a si mesmos os diferenciando uns dos outros (e mesmo dando suporte à sua comunhão ou não-mistura uns com os outros), seria, ele também, idêntico ao ser. Mas a natureza do diferente ou do outro é ser sempre relativa: por diferença relativa a outrem é que se funda sua possibilidade enquanto tal. $\mathrm{O}$ ser, por outro lado, participa tanto da possibilidade de ser auta kath'hautá, daquilo que é absolutamente, quanto da via pros alla, ou seja, daquilo que é por diferença, relativamente. Assim, o outro ou a diferença não pode ser idêntico ao ser, mas tem que ser considerado um quinto gênero maior.

O ponto sensível da questão se encontra justamente nessa relação entre o ser e o outro. O Estrangeiro, como se sabe, não deseja repetir a via encontrada por Parmênides - e que fundava a própria possibilidade da valorização sofística do não-ser, como no caso de Górgias -, via que aniquilava de saída a possibilidade do não-ser, por compreendê-lo como oposto radical do ser. Ora, na questão do outro (ou da diferença) no Sofista de Platão, nos encontramos novamente diante do problema do não-ser. Mas aqui cada gênero participa do ser, e o outro é aquilo que possibilita as

\begin{tabular}{|c|c|l|l|c|c|}
\hline intuitio & $\begin{array}{c}\text { ISSN } \\
1983-4012\end{array}$ & Porto Alegre & Vol.7- $\mathrm{N}^{\mathrm{o}} .2$ & $\begin{array}{c}\text { Novembro } \\
2014\end{array}$ & p. 197-213 \\
\hline
\end{tabular}


relações entre as formas. O Estrangeiro aproxima tudo aquilo que consideraríamos habitualmente como dizendo respeito ao não-ser como algo que diz respeito ao outro: "a cada vez, o 'não é' da língua comum é traduzido no discurso do Estrangeiro pelo termo positivo 'é outro que', que é a explicação da relação de participação na forma do outro" "'. É precisamente a partir da participação no outro que podemos compreender a leitura que é feita no diálogo do problema do não-ser. Enquanto a identidade de cada forma é garantida pela participação no mesmo, a alteridade própria à relação das formas umas com as outras é outorgada a cada forma pela participação no outro ou na diferença. Todos os gêneros, portanto, exceto o ser (que participa de todos os outros gêneros), participam tanto do mesmo quanto do outro/diferença. O outro, como campo do não-ser, ao contrário do legado de Parmênides, não é aqui compreendido como oposição radical ao ser, mas é lido como princípio da alteridade e da diferença. O exemplo paradigmático da combinação entre não-ser e diferença pode ser depreendido da análise que se encontra no Sofista sobre a participação do movimento nos outros gêneros.

Esta análise é sintetizada numa série de formulações que vinculam o movimento aos quatro gêneros restantes. De início, admite-se que o movimento não é repouso, isto é, que o movimento não participa do repouso, mas, mais do que isso, que em relação ao repouso como gênero, o movimento faz valer sua participação no outro: o movimento é outro ou diferente em relação ao repouso. O outro aqui equivale a afirmar a não-identidade entre movimento e repouso, fazendo do movimento uma espécie de não-ser em relação ao repouso. Ao mesmo tempo em que o movimento é o mesmo, na medida em que participa do mesmo, sendo assim caracterizada sua identidade consigo mesmo (movimento $=$ movimento), o Estrangeiro afirma igualmente que o movimento não é o mesmo, na medida em que o movimento é outro (participa do outro como gênero) em relação ao mesmo. Finalmente, a afirmação de que o movimento é e de que o movimento não é, aparentemente contraditórias, mostram sua coerência ao se compreender que o movimento participa do ser como gênero, mas, ao mesmo tempo, o movimento é outro em relação ao gênero do ser (não sendo idêntico, ou não cultivando uma relação de identidade com o ser).

A questão do outro ou da diferença se mostra, no texto de Platão, um problema que se desenvolve nos planos da relação - toda a questão da diferença depende de um jogo de relações entre os gêneros -, mas também de um questionamento sobre o problema da alteridade em relação a positividade de cada gênero, ou seja, da relação entre o ser das formas com o não-ser que cada forma "subentende". Desenvolveremos em seguida algumas considerações sobre o problema da diferença em Jacques Derrida, norteados, do mesmo modo, pelo problema da relação e da alteridade.

${ }^{11}$ MARQUES, M. P. Platão, pensador da diferença: uma leitura do Sofista. Belo Horizonte: UFMG, 2006, p.259.

\begin{tabular}{|c|c|l|l|l|l|}
\hline intuitio & $\begin{array}{c}\text { ISSN } \\
1983-4012\end{array}$ & Porto Alegre & Vol.7- $\mathrm{N}^{\mathrm{o} .2}$ & $\begin{array}{c}\text { Novembro } \\
2014\end{array}$ & p. 197-213 \\
\hline
\end{tabular}




\section{Derrida e a différance}

A questão da diferença em Derrida se inicia com uma diferença introduzida no seio do próprio termo francês différence. Ao grafar a palavra com a vogal "a", dando, assim, origem ao termo différance, Derrida marca o laço entre diferença e escrita. $\mathrm{O}$ interesse fundamental da reflexão derridiana é desvincular o laço que a escrita dita "fonética" - aquela que compreende o traço escrito como reprodução dos sons da voz - estabeleceu entre escrita e fala. Tal laço, vinculado inelutavelmente a uma determinada concepção de escrita oriunda dos sistemas de escrita tributários de algumas das línguas ocidentais, ao se universalizar como concepção filosófica ocidental da própria linguagem em seu vínculo com a escrita, seria responsável por uma forma de etnocentrismo que submeteria toda forma de escrita aos imperativos do logos. Em outras palavras, a escrita dita fonética, escrita que representa os sons da fala, teria servido de suporte para uma concepção da fala (e da escrita de maneira geral) que alcança proporções filosóficas grandiosas. Nesse contexto, o primeiro alvo da desconstrução derridiana será precisamente aquilo que ele chamou de logocentrismo.

Aristóteles definiu a voz (phoné) como o símbolo de tudo aquilo que se passa na alma ${ }^{12}$. A voz traduziria, portanto, aquilo que está contido no interior, na psyché ou na alma. A partir de tal concepção, a escrita - como simbolismo submetido à voz - seria algo subordinado e suplementar aos sons vocalizados, representando um desvio, um simbolismo de terceira ordem (alma - voz - escrita) ameaçador à derivação imediata da voz em relação à alma. Dentro dessa estrutura, o logos foi definido por Aristóteles como phoné semantiké, isto é, como voz dotada de significação ${ }^{13}$. Derrida vai dedicar grande parte de sua obra a mostrar que esse privilégio da voz intencional, o que ele chamou de fonologocentrismo ou o que foi por ele também chamado de sistema do "ouvir-se falar" ${ }^{14}$, não apenas relega ao conceito de escrita uma ideia de decadência e de submissão em relação ao "querer-dizer" transparente a si que orbita em torno da noção de intenção - concepção da voz como relação direta ao significado intencional -; mas, mais do que isso, que a necessária exterioridade da escrita em relação ao $\log o s$ - a escrita, esse "princípio corruptor" da essência do logos -, nos permitiria enxergar o papel que ela exerce silenciosamente (como rejeitada ao exterior) no estabelecimento da concepção metafísica de uma "pureza interna" do logos (pureza que seria transmitida pela fala, intencionalmente mais próxima e imediata em relação ao pensamento).

\footnotetext{
${ }^{12}$ ARISTÓTELES. Órganon. Trad.: Bini, E. Bauru: Edipro, 2010, pp. 4, 16b 26.

${ }^{13}$ A diferença entre a definição, para Aristóteles, entre o logos e o onoma, isto é, entre o logos e a palavra ou nome, consiste no fato de que a menor parte do logos, a palavra, guarda em si mesma um significado, ao passo que a menor parte da palavra, a sílaba, não significa nada. Há ainda uma diferença na Política entre a voz animal e a voz humana. Enquanto a primeira é capaz de expressar dor e prazer; a voz humana ao tornar-se logos, é capaz de produzir signos, de significar - sémeion - e, portanto de distinguir o justo e o injusto, o bem e o mal.

${ }^{14} \mathrm{O}$ chamado sistema do ouvir-se-falar é atribuído à suposta imediaticidade da voz (ainda que secundária) em relação à intenção (Husserl, Habermas, Searle) nascida na alma (Aristóteles). No entanto, como falante, sou também meu primeiro ouvinte, o que inaugura de saída uma disjunção entre aquilo que falo e a "consciência" de minha própria fala.
}

\begin{tabular}{|c|c|l|l|c|c|}
\hline intuitio & $\begin{array}{c}\text { ISSN } \\
1983-4012\end{array}$ & Porto Alegre & Vol.7- $\mathrm{N}^{\mathrm{o} .2}$ & $\begin{array}{c}\text { Novembro } \\
2014\end{array}$ & p. 197-213 \\
\hline
\end{tabular}


Ora, Derrida argumenta que não há escrita puramente fonética. Toda escrita, mesmo aquela considerada efetivamente fonética - isto é, que traduz visualmente elementos da fala -, comporta em si elementos não fonéticos - os mais evidentes seriam a pontuação, o espaçamento entre letras e palavras, a acentuação e outros -, e tal constatação o leva a analisar o princípio fundamental da teoria do signo linguístico de Ferdinand de Saussure, a saber: a diferença.

Em linhas gerais, Saussure defende a tese de que, na língua comum, do ponto de vista estrutural, a diferença é aquilo que possibilita a positivação ou audição das unidades de sons que formam as palavras (fonemas). A "positivação" dos fonemas é determinada por uma relação diferencial que possibilita que os fonemas emerjam (por diferença uns em relação aos outros) de uma massa indistinta de sons, compondo assim os arranjos que formam signos dotados de sentido. A diferença, portanto, é condição de possibilidade e de funcionamento de todo signo. E, no entanto, a diferença é, ela mesma, inaudível, não-fonética. "Se não há, portanto, escrita puramente fonética, é porque não há phonè puramente fonética" 15 , sendo a própria fonetização dependente desse "algo" nãofonético que é a diferença. Estamos bem longe aqui do onoma do Crátilo de Platão.

A diferença é aquilo que "escreve" o signo. Logo, a ideia da différance derridiana é justamente a de reinscrever o caráter não fonético na diferença ordinária, de modo a salientar o caráter de escrita que os significantes da fala, em sua relação diferencial, cultivam. Afirmar a différance, ou o caráter de escrita que os significantes da fala apresentam, não significa afirmar o sensível (que supostamente diria respeito à escrita ou ao significante) contra o inteligível (que diria respeito à fala ou ao significado). Mais do que isso, trata-se de um remetimento a uma ordem que inscreve-se para além da polaridade tradicional da filosofia - de Platão, especialmente - entre o sensível e o inteligível, ou ainda entre significante e significado. A estratégia da desconstrução é a de mostrar a participação daquilo que foi excluído ou posto fora (a escrita) na própria composição interna daquilo que se afirma (o logos ou a fala intencional em sua suposta relação direta ao logos). Mas différance não pertence nem à fala nem à escrita (no sentido corrente da palavra) propriamente, mas se inscreve no limiar entre ambas, vinculando fala e escrita numa unidade que interdita a separabilidade dos dois termos em uma simples polaridade.

A différance é aquilo que não tem jamais presença, permanecendo sob o fundo de tudo aquilo que se mostra, como condição de possibilidade invisível ou inaudível do aparecer. Derrida salienta: a diferença não é um ente presente, a diferença não é, estando, portanto, fora da lógica da presença/ausência que gere a questão dos entes. Não está em jogo, aqui, nada mais que remeta à polaridade entre ser e não-ser.

Ora, a diferença derridiana não é antecedida e nem se deixa compreender por algo que a abarque. Não há princípio originário que dê origem ao jogo de diferenças. Sendo a condição de positivação dos signos, a diferença derridiana não é antecedida e não está submetida ao ser ou a

${ }^{15}$ DERRIDA, J. "La différance". in: Marges de la philosophie. Paris: Minuit, 1972a, p. 5.

\begin{tabular}{|c|c|l|l|c|c|}
\hline intuitio & $\begin{array}{c}\text { ISSN } \\
1983-4012\end{array}$ & Porto Alegre & Vol.7- N .2 & $\begin{array}{c}\text { Novembro } \\
2014\end{array}$ & p. 197-213 \\
\hline
\end{tabular}


nenhuma ontologia (como em Platão). Ao contrário, tudo aquilo que aparece já está inscrito e permanece dependente de um puro jogo de diferenças: a escrita como campo de relações tributário da différance permanece inteiramente independente do ser, ou de uma arché que funcionaria como começo absoluto ou como garantidor da estrutura de remetimentos da escrita:

[...] nenhuma verdade transcendental e presente fora do campo da escrita pode comandar teologicamente a totalidade do campo [...] Se há certa errância no traçado [tracement] da différance, ela apenas segue a linha do discurso lógico-filosófico como seu contrário simétrico e solidário, o discurso lógico-empírico: o conceito de jogo se mantém além dessa oposição, ele anuncia, na aurora e para-além da filosofia, a unidade do acaso e da necessidade, num cálculo sem fim ${ }^{16}$.

O jogo é a ideia que comanda a teia diferencial, a dif-errância, onde a errância da diferença compõe todas as relações, sem a dependência prévia de um princípio unificador transcendental, sem referência ao ser ou a um "em-si" externo ao puro jogo da différance. A melodia seguida pela diferença aqui, respeita a partitura do verbo latino differre. No latim, esse verbo apresenta uma dupla conotação ou dupla via de compreensão.

De um lado, o verbo latino remete ao sentido mais corrente da diferença como sendo aquilo que é outro, discernível, não idêntico. Assim, a différance se apresenta sob o fundo de cada termo positivo. O mesmo equivale a uma espécie de oposição ao outro; poderíamos mesmo dizer que o mesmo é o outro diferido. Todas as oposições que comandam a história da metafísica equivalem à história da valorização de um termo em sua relação de diferença a outro - diferença que aqui contribui para a manutenção do mesmo, como em Platão. Mas Derrida identifica essa estrutura tradicionalmente metafísica para apontar de que maneira o pensamento metafísico mantém silenciosa a différance, o rastro [trace] do outro no mesmo, valorizando ou buscando purificar determinados termos de uma impregnação e relação com outros termos (esses, diretamente condenados pelo logos). Assim, poderíamos mencionar, a título de exemplo, a relação diferencial que compõe algumas da mais clássicas oposições filosóficas ou metafísicas. O sensível, portanto, se constitui como sendo o inteligível diferido, a cultura se afirma como sendo a natureza diferida, ou ainda a physis como o outro do nomos, ou da história, ou da liberdade, ou do espírito, etc.

Em sua outra via, o verbo diferre indica o sentido de uma temporalização. Nesse sentido, diferir aponta para algo que é adiado, remetido para um tempo vindouro, confiado a um momento sempre mais tardio. Ora, a escrita, como campo da diferença, tem precisamente essa mesma relação temporal com a ontologia e com o sentido: na medida em que o significado, o "ser" dos significantes da escrita torna-se promessa adiada, toda ontologia é encarada como uma hantologie (justaposição do verbo hanter, assombrar, perseguir e do logos, num jogo com a ontologia filosófica). A ideia do signo como forma de diferir em relação à "coisa” já se encontra na concepção clássica do signo linguístico e passa por Saussure. Na impossibilidade de apontar algo em seu ser presente, em sua própria presença imediata, lançamos mão do signo na intenção de significar. Daí a ideia de que o signo representa a

${ }^{16}$ DERRIDA, J. "La différance". in: Marges de la philosophie. Paris: Minuit, 1972a, p. 7.

\begin{tabular}{|c|c|l|l|c|c|}
\hline intuitio & $\begin{array}{c}\text { ISSN } \\
1983-4012\end{array}$ & Porto Alegre & Vol.7- $\mathrm{N}^{\mathrm{o} .2}$ & $\begin{array}{c}\text { Novembro } \\
2014\end{array}$ & p. 197-213 \\
\hline
\end{tabular}


coisa em sua ausência, ou simplesmente, de que o signo mata a coisa, que o signo toma o lugar da coisa. O signo linguístico, portanto, re-presenta ou busca presentificar a coisa em sua ausência. É parte da estrutura do signo, conforme ele é concebido classicamente, diferir, apontar para além, "o signo seria, então a presença diferida"17.

Seria fundamental à estrutura do signo a função de mediação entre a presença adiada e a ausência provisória que o signo busca suprir. Ora, a desconstrução visa pôr em questão o fundamento metafísico por trás de tal ausência provisória. Em outras palavras, Derrida visa apontar que a presença original e definitiva da coisa - provisoriamente perdida no momento em que nos utilizamos do signo linguístico - supõe uma "essência verdadeira" da coisa, uma "presença efetiva" da coisa, fora do jogo diferencial da linguagem, externa e transcendente à própria linguagem (que ganharia função ao denotar a coisa em sua ausência temporária); "os valores de origem, de arché, de telos, de eskhaton, etc. sempre denotaram a presença - ousia, parousia, etc.”. Assim, atingir o que permanece inquestionado nesse valor de presença, na ideia de um originário para além de toda a linguagem, requisita "questionar o caráter secundário e provisório do signo, opor a ele uma différance 'originária"”, . Na origem, se há origem, não está a coisa presente, em sua essência permanente e idêntica a si mesma, auta kath 'hautá, mas, só se encontra o puro jogo da différance. A "coisa mesma" escapa $^{19}$.

O signo linguístico de Saussure, por permanecer ligado à representação e, portanto, à apresentação da coisa em sua ausência - seja o referente ou o sentido -, precisou lançar mão de um segundo princípio, como que para corrigir ou limitar o princípio fundamental da diferença, a saber: o arbitrário do signo. Se, para Saussure, arbitrário e diferencial são princípios linguísticos correlatos, Derrida argumenta que o arbitrário do signo visa estabilizar o signo visando a representação, o significado, o sentido ideal. Rompendo o signo de sua dualidade ideal (significado), material (significante), o pensamento derridiano libera a différance dos constrangimentos representacionais. $\mathrm{O}$ puro jogo diferencial, isto é, a différance, é aquilo que constitui o sistema dos signos, sistema que não é composto por termos plenos, senão por relações:

Todo conceito está por direito e essencialmente inscrito em uma cadeia ou em um sistema no interior do qual ele remete à outro, aos outros conceitos, por um jogo sistemático de diferenças. Tal jogo, a différance, não é mais simplesmente um conceito, mas é a possibilidade da conceitualidade, do processo e do sistema conceitual em geral ${ }^{20}$.

\footnotetext{
${ }^{17}$ DERRIDA, J. "La différance". in: Marges de la philosophie. Paris: Minuit, 1972a, p. 9.

${ }^{18}$ DERRIDA, J. "La différance". in: Marges de la philosophie. Paris: Minuit, 1972a, p. 10.

${ }^{19}$ La chose même se derobe toujours, referência a uma famosa frase de Derrida que atravessa toda sua obra.

${ }^{20}$ DERRIDA, J. "La différance". in: Marges de la philosophie. Paris: Minuit, 1972a, p. 11.
}

\begin{tabular}{|c|c|l|l|c|c|}
\hline intuitio & $\begin{array}{c}\text { ISSN } \\
1983-4012\end{array}$ & Porto Alegre & Vol.7- No.2 & $\begin{array}{c}\text { Novembro } \\
2014\end{array}$ & p. 197-213 \\
\hline
\end{tabular}




\section{Conclusão}

Ao percorrer brevemente o problema da diferença em Platão e em Derrida, percebemos os problemas que atravessam ambas as concepções de modo equivalente. Platão visa conceber, sem medo de tocar o problema do não-ser como "outro", a participação da diferença entre os megista gene. A diferença em Platão, finda por se relacionar com o mesmo e marca sua participação e submissão ao ser como princípio ontológico fundamental. Nesse sentido, a diferença se constitui como fundamento da possibilidade do mesmo ao mesmo tempo em que está, assim como os outros quatro gêneros, submetida ao ser. O ser, como princípio unificador dos gêneros, permanece imperturbado em seu lugar de princípio fundamental da ontologia platônica. Deste modo, ao pensar a diferença do ponto de vista "relacional", ligada à relação pros alla entre os gêneros, Platão vincula a diferença inexoravelmente à questão do mesmo. No entanto, ele é ao mesmo tempo capaz de salvar a relação de identidade do gênero pela via auta kath 'hautá sem incômodos, uma vez que o mesmo guarda um laço direto com o ser que o abarca e transcende.

A desconstrução, por sua vez, visa pensar a diferença fora de qualquer relação originária ou transcendental, fora, portanto, de qualquer pensamento que a remeta a um princípio primeiro, garantidor de uma referência ontológica isenta de laço, fora ou externa ao puro jogo diferencial. Derrida reinscreve a diferença, antes de mais nada, em seu laço com o outro - isto é, com o rastro, trace, essa marca do outro que permanece silenciosa em cada termo positivo - e do mesmo modo, com a linguagem. A différance não é um princípio originário, mas, ao contrário, é o puro jogo diferencial ou relacional que interdita a suposição de qualquer princípio primeiro totalizante:

O que se escreve différance, será, portanto, o movimento de jogo que "produz" [...] essas diferenças, esses efeitos de diferença. Isso não quer dizer que a diferença que produz diferenças seja antes delas, em um presente simples e em si imodificado, indiferente. A différance está na "origem" não-plena, não-simples, origem estruturada e diferente das diferenças. O nome "origem" não convém mais, portanto (DERRIDA, 1972a, p. 12).

O pensamento da différance visa pensar esse jogo diferencial fora de toda referência prévia ao ser e a todo princípio ontológico que abarcaria o jogo da escrita em uma referência à representação. Se a linguagem depende da diferença, a escrita dos termos positivos depende puramente de uma relação pros alla que produz os significantes. Não há, para Derrida, referência prévia e externa à différance, a uma essência, presença a si ou ousia. A desconstrução deseja liberar a diferença de sua submissão ao ser (Platão) e ao arbitrário do signo (Saussure). Assim, tornou-se possível pensar o jogo diferencial divorciado de qualquer essência ontológica (ser/ousia) ou de qualquer vínculo com a representação de uma presença ausente (significado/arbitrário).

\begin{tabular}{|c|c|l|l|c|c|}
\hline intuitio & $\begin{array}{c}\text { ISSN } \\
1983-4012\end{array}$ & Porto Alegre & Vol.7- $\mathrm{N}^{\mathrm{o} .2}$ & $\begin{array}{c}\text { Novembro } \\
2014\end{array}$ & p. 197-213 \\
\hline
\end{tabular}




\section{Referências}

ARISTÓTELES. Catégories et De l'interprétation. Trad.: Tricot, J. Paris: Vrin, 2008.

. Órganon. Trad.: Bini, E. Bauru: Edipro, 2010.

CASSIN, B; LORAUX, N; PESCHANSKI, C. Gregos, bárbaros, estrangeiros: a cidade e seus outros. Trad.:

Oliveira, A; Leão, L. Rio de Janeiro: 34, 1993.

DERRIDA, J. De la grammatologie. Paris: Minuit, 1967. "La différance". in: Marges de la philosophie. Paris: Minuit, 1972a.

"La pharmacie de Platon". in: La dissémination. Paris: Seuil, 1972b.

"Nous autres grecs". in: CASSIN, B. Nos grecs et leurs modernes. Paris: Seuil, 1992.

Khôra. Paris: Galilée, 1993.

DERRIDA, J; DUFOURMANTELlE, A. Da hospitalidade. Trad.: Romane, A. São Paulo: Escuta, 2003.

GOLDSCHIMIDT, V. Os diálogos de Platão: estrutura e método dialético. São Paulo: Loyola, 2010.

MARQUES, M. P. Platão, pensador da diferença: uma leitura do Sofista. Belo Horizonte: UFMG, 2006.

PLATÃO. Timée. Trad.: Tricot, J. Paris: Flammarion, 1995.

. Sofista (ou do Ser). Trad.: Bini, E. In: Diálogos I. Bauru/São Paulo: Edipro, 2007.

SAUSSURE, F. Cours de linguistique générale. Paris: Payot, 1995.

Artigo recebido em: 25/08/2014

Aprovado em: 06/10/2014 